\title{
Disseminated Intravascular Coagulation, CTCAE
}

National Cancer Institute

\section{Source}

National Cancer Institute. Disseminated Intravascular Coagulation, CTCAE. NCI

Thesaurus. Code C55273.

A disorder characterized by systemic pathological activation of blood clotting mechanisms which results in clot formation throug hout the body. There is an increase in the risk of hemorrhage as the body is depleted of platelets and coagulation factors. 